\title{
Atualidades/Actualities
}

\section{PLANEJAMENTO DE BANCO DE LEITE HUMANO E CENTRAL DE INFORMAÇOEES SOBRE ALEITAMENTO MATERNO}

Maria Alice Altenburg de Assis *

Evanguelia Kotzias Atherino dos Santos**

Denise Maria Guerreiro Vieira da Silva***

ASSIS, M. A. A. de et al. Planejamento de banco de leite humano e central de informaçōes sobre aleitamento materno. Rev. Saúde públ., S. Paulo, 17:406-12, 1983.

RESUMO: Apresenta-se o planejamento das atividades e da área física do Banco de Leite Humano e Central de Informaçōes sobre Aleitamento Materno da Maternidade Carmela Dutra, da Fundação Hospitalar de Santa Catarina. Com a implantação deste serviço, procura-se atender as necessidades dos bebes intermados em Unidades de Tratamento Intensivo das Maternidades e Hospitais Infantis desta Fundação. Além de coletar, analisar, armazenar e processar adequadamente o leite doado por nutrizes voluntárias, săo realizadas atividades educativas e de incentivo ao aleitamento materno junto a comunidade e aos profissionais de saúde. pưblica.

UNITERMOS: Banco de leite humano. Aleitamento. Educação em saúde

\section{INTRODUÇAO}

A utilização do leite e colostro humano revelou-se em vários estudos relatados como um método eficaz de dominar as epidemias de diarréia aguda produzida por $E$. coli enteropatogênica, observadas com frequiência nas Unidades de Internação dos recém-nascidos de alto risco ${ }^{3,7,8}$.

Crianças prematuras ou de baixo peso ao nascer possuem maiores exigências de proteinas e de cálcio, em relação ao bebê a termo, devido a maior aceleração do crescimento 6 . 0 mesmo năo ocorre quando 0 pré-termo recebe o colostro humano que apresenta elevado teor de proteinas e cálcio ${ }^{6}$.
Muitos problemas impossibilitam o uso do leite humano para essas crianças. Além da dificuldade encontrada pelos recém-nascidos de alto risco de sugar o seio materno, observa-se em alguns casos a falta de interesse da equipe de saúde para orientar a mãe sobre a retirada manual do leite.

Ocorrem também outros problemas de ordem prática, tais como a dificuldade de obter-se leite, em quantidade suficiente, de mães que, por alguma razão, estão impossibilitadas de amamentar ou, em alguns casos, a falta de interesse da equipe de saúde para facilitar o acesso da mãe às

- Da Fundação Hospitalar de Santa Catarina. R ua Irmã Benwarda, No $41-88000$ - Florianópolis. SC - Brasil.

* Da Maternidade Carmela Dutra. Rua Irma Benwarda, $\mathbf{S} / \mathrm{N} \%$ - 88000 - Florianópolis, SC - Brasil.

*m* Do Departamento de Enfermagem da Universidade Federal de Santa Catarina. Cidade Universitárla - 88000 - Florlanopolis, sc - Brasll. 
ASSIS, M.A.A. de et al. Planejamento de banco de leite humano e central de informacōes sobre aleitamento materno. Rev. Saude publ., S. Paulo, 17:406-12, 1983.

Unidades de Tratamento Intensivo, onde permanececm seus bebês ?

Encontrar um suprimento de leite suficiente para tais bebês é um problema que não se resolve somente com doações de outras mães internadas nas Unidades de Puerpério. As doações são irregulares $\mathrm{e}$ o volume que se obtem, muitas vezes, não corresponde às necessidades, em geral, dos prematuros 2 .

Em hospitais infantis, onde estão internados os bebês seriamente doentes, com intolerância gastrintestinal ou submetidos a cirurgias, a dificuldade é considerável devido a ausência constante das doadoras, como sucede nas Maternidades ${ }^{2}$.

A implantação de um Banco de Leite Humano pode constituir um valioso recurso para a recuperação dessas crianças, pois se define como uma área física capacitada a coletar, armazenar e distribuir adequadamente o leite humano.

Bancos de leite humano foram implantados na Inglaterra e nos Estados Unidos, antes da II Guerra Mundial, sucedendo-se um período de desinteresse pelo uso de leite humano na alimentação dos recém-nascidos de alto risco, devido as abandono da prática do aleitamento materno ${ }^{4}$.

Bancos de leite mais sofisticados foram implantados na Inglaterra, na década de 1970, e entre seus serviços incluiam-se análises nutricionais e bacteriológicas das amostras 10 .

O Brasil já possui bancos de leite humano na maioria de seus Estados, porém há necessidade de divulgar suas atividades e características da área física 2 .

No decorrer da Campantia Nacional de Incentivo ao Aleitamento Materno, houve recomendações no sentido de que os bancos de leite também desenvolvessem atividades que estimulassem o aleitamento natural.

Acatando a recomendação, a Fundaçăo Hospitalar de Santa Catarina implantou, na Maternidade Carmela Dutra, o Banco de
Leite Humano e Central de Informações sobre Aleitamento Materno, que vem funcionando satisfatoriamente há cerca de um ano.

O presente trabalho apresenta o planejamento efetuado para o referido setor, oferecendo subsídios às entidades que desejarem implementar projeto dessa natureza.

\section{BANCO DE LEITE HUMANO E CENTRAL DE INFORMAÇOES SOBRE ALEITAMENTO MATERNO}

\subsection{OBJETIVOS}

\subsubsection{Objetivo geral}

Desenvolver atividades que atendam à filosofia do projeto e garantam o acesso da população alvo ao Banco de Leite.

\subsubsection{Objetivos especificos}

- Coletar leite humano possibilitando estoque regular para suprir a demanda.

- Organizar cadastro das doadoras para possibilitar a coleta domiciliar.

- Distribuir o leite às maternidades e hospitais infantis, respeitando os critérios de prioridade estabelecidos.

- Propiciar às doadoras e seus dependentes menores, condições favoráveis de atendimento médico, nutricional e social.

- Prestar informações de natureza técnico-científica à comunidade, visando contribuir para o estímulo as aleitamento natural.

\subsection{GRUPO ALVO}

- Recém-nascidos prematuros.

- Recém-nascidos de baixo peso para a idade gestacional.

- Crianças imunologicamente deficientes.

- Recém-nascidos com enterocolite necrotizante.

- Crianças alérgicas a outros leites.

- Doadoras de leite

- Gestantes, puérperas e nutrizes. 
ASSIS, M.A.A. de et al. Planejamento de banco de leite humano e central de informaçōes sobre aleitamento materno, Rev. Saúde públ., S. Paulo, 17:406-12, 1983.

\subsection{ATIVIDADES}

O leite humano é coletado de acordo com as técnicas assépticas estabelecidas, no setor e a domicilio.

Um estoque satisfatório é obtido sempre que se realiza campanhas de divulgação nos meios de comunicação, para a população em geral, sensibilizando-se o profissional de saúde da área materno-infantil das clínicas particulares e da universidade.

Diariamente, a equipe previamente treina$\mathrm{da}$, orienta e encaminha as puérperas da maternidade para comparecerem ao Banco de Leite.

Realiza-se um trabalho paralelo junto às mães de recém-nascidos de alto risco, que já receberam alta, a fim de continuarem a retirar leite no Banco, com o intuito de manter o aleitamento e prover o filho com o aleitamento natural.

Além da coleta do leite, as doadoras são orientadas quanto às vantagens e técnicas do aleitamento materno, sendo enfatizada a importância das doações.

As doadoras voluntárias, no período pós-hospitalar, são orientadas sobre a coleta domiciliar, caso não possam comparecer ao Banco. Seu endereço é anotado para que diariamente um profissional da equipe efetue, em sua casa, a retirada do leite e the dê maiores orientações. Bem orientada, a mãe que reside distante do Banco de Leite, retira ela própria o leite e estoca no congelador para que uma vez por semana seja recolhido pelo carro do Banco.

As mães carentes de recursos recebem passes de ônibus, doados pela Fundação Legião Brasileira de Assistência, para comparecerem ao Banco e amamentarem seus filhos internados nas Unidades de Tratamento Intentivo; são também cadastradas no Programa de Nutrição em Saúde, com direito a receber alimentos do Instituto Nacional de Alimentação e Nutrição (INAN).
No Banco de Leite, a estocagem é realizada na geladeira se a utilização for feita dentro de 24 horas, caso contrário, processa-se o congelamento em congeladores comerciais, até um período de seis meses.

Para controle da qualidade microbiológica do leite, analisa-se três amostras por semana, pesquisando-se os microorganismos mais comumente encontrados no leite humano, segundo a bibliografia consultada ${ }^{5,9}$. A qualidade é avaliada seguindo-se os padrões de referência citados na literatura 2,10 .

A requisição do leite é feita através dc formulário próprio, contendo dados sobre o volume solicitado, nome, intercorrência clínica da criança e volume cedido.

Atividades educativas visam divulgar a importância do aleitamento materno à comunidade, orientar as instituições sobre montagem e operacionalização de Bancos de Leite e incentivar a criação da Liga do Leite Materno em Santa Catarina.

Através de estágios são treinados pessoal de nivel superior, médio e operacional da área materno-infantil, para que de alguma forma contribuam no desenvolvimento dos trabalhos do Banco de Leite.

\subsection{LOCALIZAÇAO E AREA FISICA}

O Banco de Leite Humano e Central de Informaçōes sobre Aleitamento Materno localiza-se na Maternidade Carmela Dutra, em local de fácil acesso ao público.

A área física é composta de cinco salas por se constituir no Banco de Leite Central. Postos de Coleta, subordinados tecnicamente ao Banco de Leite Central e com estrutura física composta de apenas duas salas (recepção e coleta), foram montados em outras maternidades e hospitais infantis da Fundação Hospitalar de Santa Catarina.

O Banco de Leite Central esta constituido das seguinte salas, dispostas conforme planta em anexo. 
ASSIS, M.A.A. de et al. Planejamento de banco de leite humano e central de informaçóes sobro aleitamento materno. Rev. Saúde públ., S. Paulo, 17:406-12, 1983.

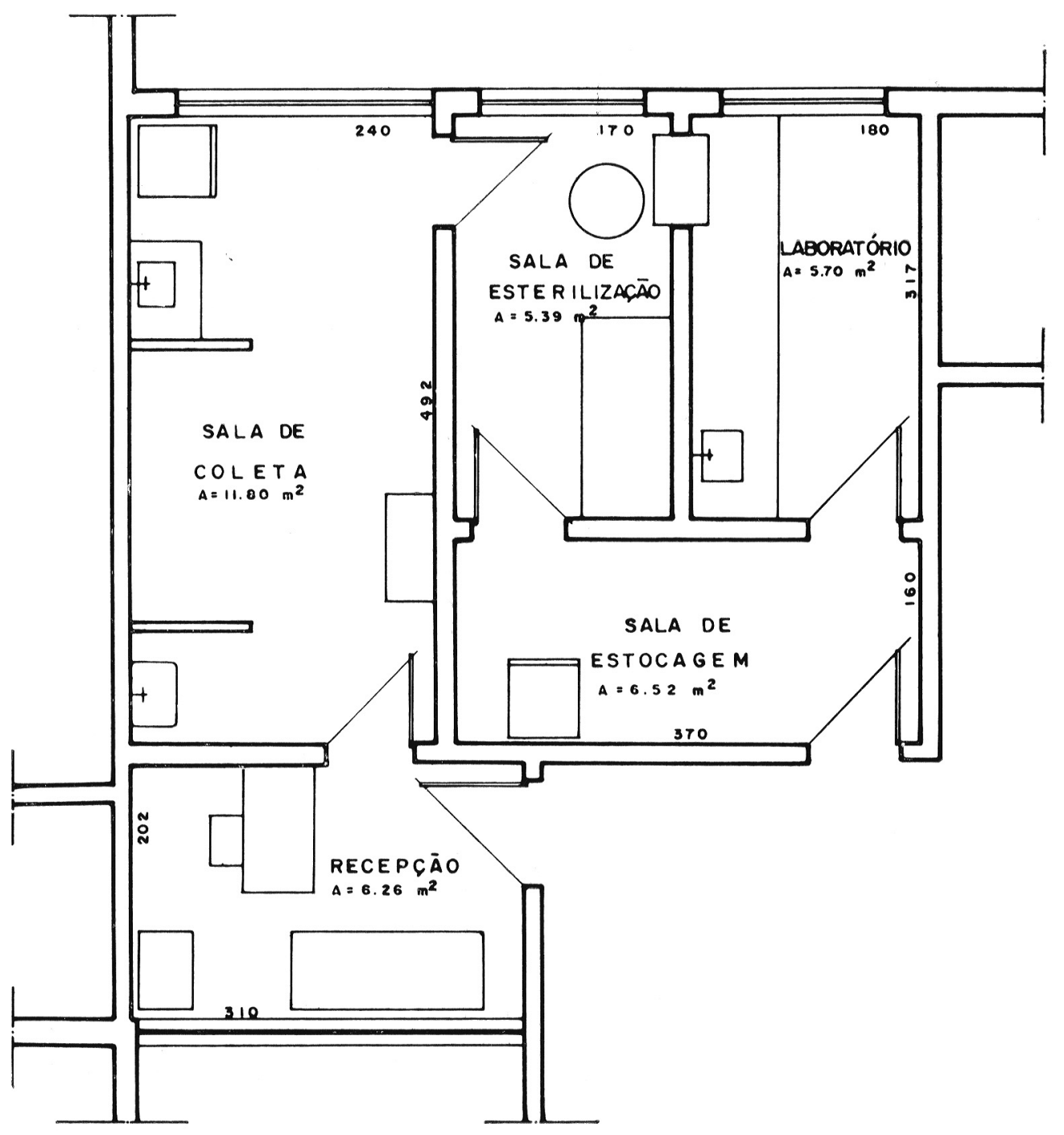

2.4.1. Sala de Recepşão e Triagem das Doadoras

- Area: $6,26 \mathrm{~m}^{2}$

- Piso: lajota

- Revestimento: tinta plástica

- Finalidade: destina-se ao atendimento de gestantes, puérperas e nutrizes no que diz respeito as orientações sobre aleitamento materno, encaminhamento para coleta e registro dos dados médico-sociais.

- Máterial permanente:

- Telefone

- Mesa com gavetas laterais

- Cadeira de madeira

- Banco, sofá ou poltrona para quatro pessoas. 
ASSIS, M.A.A. de et al. Planejamento de banco de leite humano e central de informaçós sobre aleitamento materno. Rev. Saude públ., S. Paulo, 17:406-12, 1983.

- Armário

- Arquivo para fichas

- Material de consumo

- Fichas para o registro de dados médico-sociais

- Manuais e folhetos sobre aleitamento materno

- Bandeja para lanches

- Passes de ônibus

\subsubsection{Sala de Coleta do Leite}

- Area: $11,80 \mathrm{~m}^{2}$

- Piso: lajota

- Revestimento: azulejo

- Finalidade: coletar leite humano de acordo com as técnicas assépticas estabelecidas, fazer aplicação de calor, massagem nas mamas, usar oxitocina sintética nas clientes que apresentarem ingurgitamento mamário; guardar o leite coletado na geladeira por um periodo máximo de $24 \mathrm{~h}$.

- Material permanente:

- Três bombas elétricas extratoras de leite

- Vinte bombas manuais

- Uma geladeira

- Um ar condicionado

- Duas banquetas giratórias

- Dois carrinhos com rodizio para as bombas elétricas

- Duas divisórias de material divelux com vidro, a fim de separar a área de coleta das pias

- Um armário para guardar aventais, gorros, máscaras, propés, camisolas com aberturas nos seios.

- Um armário para guardar mamadeiras e bombas manuais

- Material de consumo

- Bombas manuais

- Toalheiro de papel

- Adaptadores de sucção para seio

- Borracha intermediária para bombas elétricas

- Mamadeiras de plástico
- Mamadeiras de vidro

- Escova para lavar mamadeira

- Bolsa de água quente

- Sabão

- Sabonete

- Alcool

- Camisolas com abertura nos seios

- Hamper para roupas usadas

- Sacos de hamper

- Propés

- Máscaras

- Gorros

- Balde plástico para lixo

\subsubsection{Sala de Esterilizaçâo do Material}

- Área: 5,39 m²

- Piso: lajota

- Revestimento: azulejo

- Finalidade: esterilizar e desinfetar o material utilizado na sala de coleta, armazenamento e laboratório

- Material permanente:

- Uma estufa

- Uma autoclave

- Um armário

- Material de consumo

- Cubas para desinfetante

- Desinfetantes e desincrostantes

\subsubsection{Sala de Estocagem}

- Área: $6,52 \mathrm{~m}^{2}$

- Piso: cerâmica

- Revestimento: azulejo

- Finalidade: estocar leite humano disponível "in natura" ou liofilizado em freezer, após análise de sua qualidade microbiológica

- Material permanente:

- Um "freezer"

- Um liofilizador

- Material de consumo

- Gelo seco 
ASSIS, M.A.A. de et al. Planejamento de banco de leite humano e central de informaçóes sobre aleitamento materno. Rev. Saúde públ., S. Paulo, 17:406-12, 1983.

\subsubsection{Sala de Laboratório}

- Área: $5,70 \mathrm{~m}^{2}$

- Piso: cerâmica

- Revestitmento: azulejo

- Finalidade: analisar o leite humano quanto a qualidade microbiológica, nutricional e imunológica

- Material permanente:

- Uma balança com capacidade para uma grama

- Uma estufa

- Um microscópio

- Um bico de bünsen

- Um contador de colônias microbiológicas

- Um armário

- Material de consumo

- Meios de cultura

- Placas de imunodifusão radial

- Reagentes diversos

\subsection{RECURSOS HUMANOS}

Poderá ser utilizada a equipe técnica multiprofissional da própria instituição, com- posta por enfermeiros, nutricionistas, tecnólogo de alimentos, médicos pediatras, obstetras e assistentes sociais.

Além da equipe técnica pode-se contar com o trabalho de uma atendente de enfermagem e de estagiários de cursos universitários da área de saúde.

\subsection{INSTITUIÇOES PARTICIPANTES}

- Fundação Hospitalar de Santa Catarina

- Maternidade Carmela Dutra

- Hospital Infantil Joana de Gusmão

- Maternidade Dr. Carlos Corrêa

- Secretaria da Saúde de Santa Catarina

- Departamento Autônomo de Saúde Pública

- Fundação Legião Brasileira de Assistência

- Prefeitura Municipal de Florianópolis

- Clubes de Serviço (Rotary, Lions, Casa da Amizade)

- Hospital Florianópolis

- Hospital Universitário

ASSIS, M. A. A. de et al. [Planning of the human milk bank and the information center on breast feeding]. Rev. Saúde públ., S. Paulo, 17:406-12, 1983.

ABSTRACT: The planning of the activities and the layout of the Human Milk Bank and Information Center on Breast Feeding of the Carmela Dutra Maternity Hospital of the Santa Catarina Hospital Foundation (Brazil) are presented. The implantation of this service seeks to attend to the necessities of babies under treatment in Intensive Care Units of the Maternity and other children's hospitals of this Foundation. Besides collecting analising, storing and processing, adequately, the milk donated by volunteer wet-nurses, educational and promotional activities related to breast feeding are carried out in the community and among health profissionals.

UNITERMS: Human milk banks. Breast feeding. Health education. 
ASSIS, M.A.A. de et al. Planejamento de banco de leite humano e central de informações sobre aleitamento materno. Rev. Saúde públ., S. Paulo, 17:406-12, 1983.

\section{REFERENCIAS BIBLIOGRAFICAS}

1. APPLEBAUM, R.M. Ténicas modernas para o êxito da amamentação. Maceió, La Leche League de Maceió, 1970.

2. ASSI\$, M.A.A. Estudos sobre a preservação do colostro humano para bancos de leite. Campinas, 1981, [Dissertação de Mestrado - Faculdade de Engenharia de Alimentos e Agrícola da UNICAM].

3. BULLEN, J.J. \& ROGERS, H.J. Iron binding proteins in milk and resistance to Escherichia coli infections in infants. Brit. med. J., 1:69-75, 1972.

4. DAVY, S.T. Human milk banks. Nurs. Times, 15:758-61, 1975.

5. LUCAS, A. \& ROBERTS, C.D. Bacteriological quality control in human milk-banking. Brit. med. J., 1:80-2, 1979.

6. NORDIO, S.; LEVI, U. \& ANTENER, I. Aspectos nutricionais e metabólicos do aleitamento ao seio. An. Nestlé, S. Paulo, (103) :80-9, 1979 .
7. ROSS, C.A.C. \& DAWES, E.A. Resistance of the breast-fed infant to gastro-enterites. Lancet, 15:994-8, 1954.

8. SVISKY-GROSS, S. Pathogenic strains of coli (0.111) among prematures and the use of human milk in controlling the outbreak of diarrhea. Ann. Paediat., $190: 109-15,1958$.

9. TORRES-GOITIA, J.; FERNANDEZ, F.R.; FERNANDEZ, P.R.; FERREIRA, S.M. \& RIZZADINI, P.M. Estudos en lactancia materna. I. Resistencia de la leche materna a la contaminación bacterlana. Bol. med. Hosp. inf., 36:599-604, 1979 .

10. WILLIAMSON, S.; HEWITT, J.H.; FINUCANE, E. \& GAMSU, H.R. Organization of bank of raw and pasteurized human milk for neonatal intensive care. Brit. med. J., 1:393-6, 1970 .

Recebido para publicaçāo em 02/05/198\$ Aprovado para publicaçāo em 08/08/1983 